Article

\title{
An Attribute-Based Evaluation Framework for Sustainable Scientific Instruments Platforms
}

\author{
Xiaobo Wang *, Xueru Zhao and Caixia Zhang
}

check for updates

Citation: Wang, X.; Zhao, X.; Zhang, C. An Attribute-Based Evaluation Framework for Sustainable Scientific Instruments Platforms. Sustainability 2021, 13, 11842. https://doi.org/ $10.3390 /$ su132111842

Academic Editor:

Jurgita Antuchevičienè

Received: 13 September 2021

Accepted: 22 October 2021

Published: 26 October 2021

Publisher's Note: MDPI stays neutral with regard to jurisdictional claims in published maps and institutional affiliations.

Copyright: (c) 2021 by the authors. Licensee MDPI, Basel, Switzerland. This article is an open access article distributed under the terms and conditions of the Creative Commons Attribution (CC BY) license (https:/ / creativecommons.org/licenses/by/ $4.0 /)$.
Northwest Institute of Eco-Environment and Resources, Chinese Academy of Sciences, Lanzhou 730000, China; zxr@lzb.ac.cn (X.Z.); zhangcaixia@lzb.ac.cn (C.Z.)

* Correspondence: wangxiaobo@lzb.ac.cn

\begin{abstract}
Scientific instrument platforms (SIPs) suffer from a lack of opinion and suggestions on sustainable operation management, leading to widely poor operation status nowadays. It is possible to guarantee the quality and efficiency of scientific and technological innovation activities and to improve the economic and social benefits of scientific and technological resources by constructing a framework system to promote the sustainability of the operation and management for SIPs. To meet the examination and evaluation requirements of the current operation and management of SIPs in China, this paper aims to establish an evaluation framework composed of indicators and attributes running through the construction and development of the SIPs from four aspects of learning and growth, process management, customers, and finance. Based on the existing research and operation practice, and according to the knowledge and preference of 627 SIP stakeholders, factor analysis has been adopted to extract and validate the hierarchical structure containing key sustainability indicators. The results show that the attribute characteristics of sustainable operating management for SIPs involve four significant dimensions of target positioning, team building, internal process control, and external service, among which the first and third ones have relatively higher priority. An effective and reliable evaluation tool is identified to be designed and provided for SIP operating management, which can also be used for self-evaluation and unified management of the sustainable operation of SIPs.
\end{abstract}

Keywords: scientific instrument platform; operation and management; factor analysis; sustainability; evaluation

\section{Introduction}

At the beginning of this new century, scientific instrument platforms (SIPs) in China and the world have entered a brand-new stage of rapid development. A SIP refers to a technological supporting and organizational sub-unit independently established by the scientific research institutes, universities, and colleges, and a few research enterprises, with a series of large-scale scientific instruments and equipment and a group of full-time scientific and technological personnel. SIPs usually operate and maintain the scientific instruments and equipment to devise new methods of inspection and testing, exploit new techniques for technological advances, and provide comprehensive services for innovation bodies such as principal investigators and general science and technology practitioners both inside and outside their management units. Satisfactory SIP management gives the basis of effective utilization of scientific instruments and solid support to scientific and technological innovation activities [1]. With China's social and economic development, for example, scientific activities and basic research have been developed vigorously, pushing the procurement and construction of valuable instruments and laboratory platforms to reach new heights. By 2020, the number of large-scale scientific instruments with an original value of not less than 500,000 Chinese Yuan in China has exceeded 101,000, involving more than 4000 management units [2]. A part of these institutions has built open and sharing platforms by concentrating the scientific and technical resources, thus making them 
receive consecutive funding from the central competent authorities and local scientific departments. Yet, most of them have suffered from several obstacles to stability and sustainability, leading to a struggling operating condition [3]. It has become the key to achieving the economic and social benefits of public scientific and technological resources to solve the sustainability problems of these SIPs, and to improve the utilization and sharing rate of scientific instruments and strengthening the validity of technological supports.

Substantial examples of sustainability discussion within scientific organizations have already sprung up since the last decade in the form of experience describing and qualitating assumptions [3]. There is a tendency that quantitative research on SIPs may bring in a new sight and supplement corporate sustainability for management science. Anyhow, the focus of corporate sustainability between scientific and social organizations is conceivably diverse and discrepant. Unlike most corporate organizations and group firms, SIPs in China currently operate in a non-profit-making mode. With insufficient support of funding, many platform executives and their technical personnel would have to let their SIPs serve as a publicly serviceable laboratory by experimentation, analysis, and new approaches for a little profit to afford their own performance salary. It is still a gray zone for the financial strategies of SIPs. Besides economic issues, SIPs involve almost no issues related to environmental protection, which makes the meaning of sustainability for SIPs drastically different from the common and conventional ones. It seems that the sustainability of SIPs cannot be truly enhanced by singly emphasizing concepts and measures such as green production, technological progress, and sustainable supply chain design [4], nor by simply promoting cost control and benefit assessment [5]. For the triple bottom line principle of economic, environmental, and social perspectives [6,7], one useful reference for the sustainable development of SIPs may be social responsibility and its relevance under a real situation. However, embedding social responsibility into a SIP's system in the current stage of social-economic development approximately means significant changes and challenges, thus does the request for facilitating the SIPs to follow the concept of sustainable development. Due to the complexity and multi-dimensional issues of sustainability, the definition of a sustainable SIP and its components must be clarified from empirically to theoretically before the quantized discussion on its operation and management. Thus, a combination of quantitative analysis with qualitative analysis and theory applications with case studying would help identify the key attributes of SIP sustainability.

The uncertainty of the external policy environment and the instability of the client market conditions have both led part of corporate organizations to directly take the formation of competitive advantages and influence as an effective way to achieve sustainability [8]. Since focusing on the components of the competitiveness of SIPs, its measurement method, and its impact on the overall sustainability of the platforms may be helpful to understand the current status of SIPs and its meaning of existing. There are at least three existing research frameworks in the previous literature for the SIP sustainability problem providing feasible insight into the sustainable operation and management of SIPs. First comes the ambidexterity theory, which means a cooperate organization can easily deal with two different and even competing matters at the same time. SIPs acquire and maintain competitiveness in the same way as most enterprise organizations do, which makes them not only effective at meeting the current business requirements but also be able to adapt to the future professional needs caused by changes in the external environment [9]. Herein, to find out the balance point of exploration and development for SIPs is a considerable way forward to sustainability. The second way is the assessment of corporate sustainability performance. To construct a performance indicator system of SIPs calls for exploration to fill a gap in this research field, it is necessary to try to sort out the inherent complex interrelationships and hierarchical structure in the operation process of these platforms [10]. According to knowledge management, optimization of performance system can help to deal with the changes of the complex dynamic environment of operation and management for SIPs [11,12]. Thirdly, balanced scorecards would be exactly helpful to identify 
what a SIP should be. In implementation and improvement, the sustainable balanced scorecard, added a view of sustainable performance evaluation [13], and the materiality balanced scorecard promoted strategic and inclusive organizational change by focusing on the stakeholder-relevant factors [14]. To reflect the effect of certain governance and strategy in achieving its objectives, sustainable enterprise excellence was a similar comprehensive evaluation system that focuses on the result of organizational dynamics, market expansion, customer awareness, and technological innovation in the process of remolding the way those modern enterprises operate [15].

However, there are so many disciplines directly involved with SIPs that the decisionmakers and managers would face the choices and constraints of operation mechanisms and management systems in the process of sustainable development [3]. Thus, the evaluation framework dominated by competitiveness cultivation may not be able to fully encompass all the connotations and natural missions of SIPs. After all, the competitiveness attribute might be one of the various factors that affect the sustainability of SIPs, just like their nature of public welfare. Although the SIPs consist of scientific instruments and technical personnel, it is different from the conventional laboratory where natural scientists conduct research with chemical and biological experiment to reach the laws of nature. There ought to be chief scientists in SIPs, who usually do not take scientific research but platform construction as the main purpose to meet the position requirements and evaluation criteria. That means neither their scientific or technological innovation achievements or students training, nor the standardized and industrialized testing services or the number of detected samples and generated income should be their main business. In this way, SIPs at this current stage of social development in China have a purity that emphasizes the central role of public technology resources and the balance between exploration and exploitation both for technological advances and social responsibilities during daily operation. Hereby, analytical testing and research and development innovation are more derivative approaches within a SIP. The way to promote the sustainable development of SIPs may be a schema where the decision-makers and top executives must first pay attention to the crucial characteristics of SIPs themselves and then find the equilibrium point for creativity and productivity. Former research has corroborated that sustainable practices cannot directly be repeated from one place to another [16], which means that no matter existing sustainable indicators or evident practical approaches are all necessarily reconsidered and reexamined before being applied to SIPs. Despite the expectation of management units of SIPs and governmental competent departments for strengthening the sustainability of SIPs, there is still a lack of guidelines and evaluation framework suitable for advising and avoiding the sustainable problems and development of SIPs. There does not seem to be any compatible measures to improve the sustainable operation and management of SIPs by the methods used to evaluate the efficiency and performance of SIPs yet [17].

Multidisciplinary, multi-dimensional, and interdisciplinary, sustainability generally refers to issues of prominent complexity and uncertainty [18], but not always. With experience and practices in plenty, the SIP sustainability could be deconstructed from nominal to practical [3]. Using the strategic framework of a balanced scorecard as the original version, this study first constructs a performance evaluation indicator system to express the universal vision under the SIP operation mode of Chinese Academy of Sciences (CAS) with a literature review and semi-structured interviews. The importance assessment opinions would be collected through a wide range of questionnaires, and the hierarchical structure of the sustainable operation management of these SIPs could be identified by exploratory factor analysis (EFA). The reliability and validity of the structural model would be tested by confirmatory factor analysis (CFA). Then, the entropy weight method is used to assign indicator weights in the assessment system, thus that a practical method, which can be applied for sustainable development evaluation, would be established. By identifying the essential attributes of sustainable development for SIPs, several suggestions are provided for the stable and efficient operation of SIPs in the discussion section. This study brings three contributions: (1) it collects the preference information of decision- 
makers, managers, and other practitioners of the CAS SIPs to obtain the key factors supporting the excellent management of SIPs; (2) it constructs a strategic framework of sustainable operation management of SIPs, which can help decision-makers and managers to implement technology and knowledge management aiming to sustainable development; (3) it offers a performance evaluation tool for the sustainable operation management of SIPs, which is referential and workable for the decision-makers both in the competent departments and the management units to strengthen the decision-making process.

\section{Literature Review}

\subsection{Theoretical Basis}

The concept of sustainable development of SIPs is derived from the category of organizational sustainability and corporate sustainability, while both the latter concept originated from the proposed sustainable development initiative of the United Nations in 1987. Operational measures such as planets, human resources, and profits within the context of global business by many scholars have facilitated the concept construction of the triple bottom line framework [19], widely applied by research and assessments. However, the triple bottom line cannot fully cover the concept of sustainable development, not considering the overlap among the economic, social, and environmental dimensions [20]. Hence, relevant studies begin to focus on the effect of efficiency [21], resilience [22], and strategic planning [23] for business and procedures within organizations instead of on the concept of sustainable performance. In this context, a sustainable, balanced scorecard that integrates social and environmental issues into the evaluation would be opportune and optional in SIP operating $[13,24]$. By improving the consideration of ecological efficiency in financial and environmental factors, a new framework combined with the mixed multicriteria decision model might complement the evaluation of the sustainable performance of enterprises and organizations [25].

Given the wide range of problems inherent in the concept of sustainability, the increasing amount of information associated with it, and the complexity of the issues themselves and the resulting information, an introduction of knowledge management could help in sustainability research [26,27]. It can also reaffirm the importance of knowledge management for the operation and management process of SIPs. Knowledge management is the main source of organizational competitive advantage and value creation [28]. The practice of knowledge management mainly consists of learning and knowledge creation culture, organizational knowledge architecture for adaptive and denotative capacity, and business models for capitalizing knowledge and capturing value [29]. Effective knowledge management strengthens information exchange among stakeholders, promotes technological innovation and institutional innovation, and is applicable to the operation and management of SIPs to ensure the sharing of communication mediums, information sources, and strategic interests between different departments and diverse staff groups [30].

As previously mentioned, the lack of effective communication among different stakeholders of the SIP may be one of the reasons for the unbalanced development and performance differences of the current SIPs [17]. The integration, openness, and autonomy of the operation and management process of SIPs can be identified as the major causes for this poor situation. Integration means the readjustment and recombination through selections and concentrations of technical personnel and large-scale scientific instruments within a sub-unit named SIP. Openness shows the characteristics and missions for the construction and operation of SIPs, which ask these technicians to take adequate advantage of the instruments and to serve various scientists in need. Moreover, autonomy signifies the innate character and running condition of the SIPs, with which the executive managers or the heads of operation can deal with daily routines and emergency services at their own disposal. This process involves the dualistic issue of exploitation and exploration, which always results in a dilemma both for the platform heads and those decision-makers. Exploitation implies the effectiveness of production services and risk avoidance, while exploration underlines uncertainty of innovation and risk-taking [31]. Specifically, the 
exploration of SIPs aims at innovation processes and innovative products, including experiment design, technology research, equipment design, and instruments development, etc. On the other hand, the exploitation or development indicates these staff should take full advantage of their instruments and skills to provide clients observation, sampling, analysis and testing, consultation, and training, and so on. In addition, those people who play a leading role would have a profound impact on the sustainability of SIPs by their ways and influences to treat this process [32]. Thus, it is necessary to consider the constructs of co-evolution, co-competence, co-opetition, and co-orientation [33] in the operation and management of SIPs before the leaders and members finally reach an agreement. According to these multi-dimensional attributes in the operating process, plural main bodies, flexile organizational forms, and non-compulsory participation are the primary characteristics of SIPs. Focusing on the sustainability of SIPs, thus we should first discuss and differentiate the practical definition of sustainability for the SIPs based on sustainable development theory, knowledge management, and relevant management theories.

\subsection{Sustainability for SIPs}

The continued use and discussion of sustainability around the world have led to an increasing number of perspectives and approaches of interpreting and disseminating this concept, as well as an intensification of its significance and importance [34]. A broad definition of sustainability focuses on inclusive well-being [35,36]. The sustainability of corporate organizations in the 21st century means a dynamic balance between the entire time horizon, organizational systems, and their stakeholders [21]. Obviously, technological innovation promises only one aspect of the organizational system and cannot achieve the overall sustainability goal from the perspective of for-profit corporate operations [37]. Meanwhile, the fervent pursuit of economic goals is often too utilitarian to let an organization be stable and sustainable [38]. For supporting systems for scientific research such as SIPs, however, innovation is both one of the Sustainable Development Goals (SDGs 9) and the core competitiveness for sustainability [39]. Without profit as an important reference factor, an organizational system that includes applied scientists, engineers, experimenters, managers, and decision-makers require institutions or incentives to carry out broad system changes in order to achieve steady-state operation at any given moment, in a given business pattern, and for a given social goal [40].

Due to the purity and multi-stakeholder's perspective attribute of SIPs, sustainable operation and management need to implement and interact at the niche level, but the purposes and performance are always manipulated and controlled at the medium level and interfered and adjusted at the macro-level [3]. In the process of innovation, the factors that impede sustainable development are to a large extent, the problems that hinder the mobilization of technological innovation activities within a system [39]. Therefore, it is helpful for the sustainable development of SIPs to clearly define their concept of technological and institutional innovation and find out the factors that hamper their innovation process. The success of scientific and technological innovation is pushed by the consumption and contribution of intellectual and financial capital. The innovation process within a SIP is an important way to realize the value of material and social capital. Here, four capital calls for talent team, operational funds, scientific facilities, and social relationships. Combined with many previous academic achievements and effective practices in the past practical experience, the innovative development needs to pay attention to the continuation and iteration of personnel, finance, instruments, and services [3]. In other words, the sustainability of SIPs can be preliminarily defined as a balance state that requests for orderly transmission of talent team, reasonable financial management, efficient utilization and updating of instruments and equipment, and steady increase of services.

\subsection{Study Protocol}

Approaches to deal with organizational sustainability problems include quantitative calculation, classical statistics, and survey study [41,42]. These kinds of work need to 
be based on an appropriative research framework. When reviewing and evaluating the sustainability of research objects, the hierarchical structure of the research framework itself and the interrelationship between the attributes and indicator dimensions should be firstly clarified [21,43]. Even so, few studies have conducted a confirmatory factor analysis on the proposed attributes system to prove the reliability and validity of the evaluation framework. As research objects rarely touched on, the sustainability evaluation model of SIPs not only needs a new evaluation framework but also requires empirical verification of the proposed model. Aiming at building a feasible indicator framework, this study adopted the form of semi-structured interviews in 2018, and communicated with 3 decision makers, 12 platform heads, and 5 business executives on the jobs of operation and management in CAS SIPs by early 2019. Herein, decision-makers were the senior leaders in the institutes and administrators of CAS headquarter's, who direct, supervise, and evaluate the operation and management of SIPs. Platform heads or managers generally are persons in charge of these platforms, who are equal to middle-level leaders but reveal different preferences due to their post properties of scientific research, technological supports, and general administration. Moreover, business executives refer to SIP practitioners such as professional technicians who are the general members of the platforms, responsible for daily affairs or specific technical services for a long time. Whereas the managers put more significant impacts on the operation of their organizations [32,44]. This study tries to contact them for different management styles as much as possible. By collecting the key information mentioned by those interviewers, the CAS SIPs could be described and deconstructed to obtain the functional structure network of the platform, as shown in Figure 1.

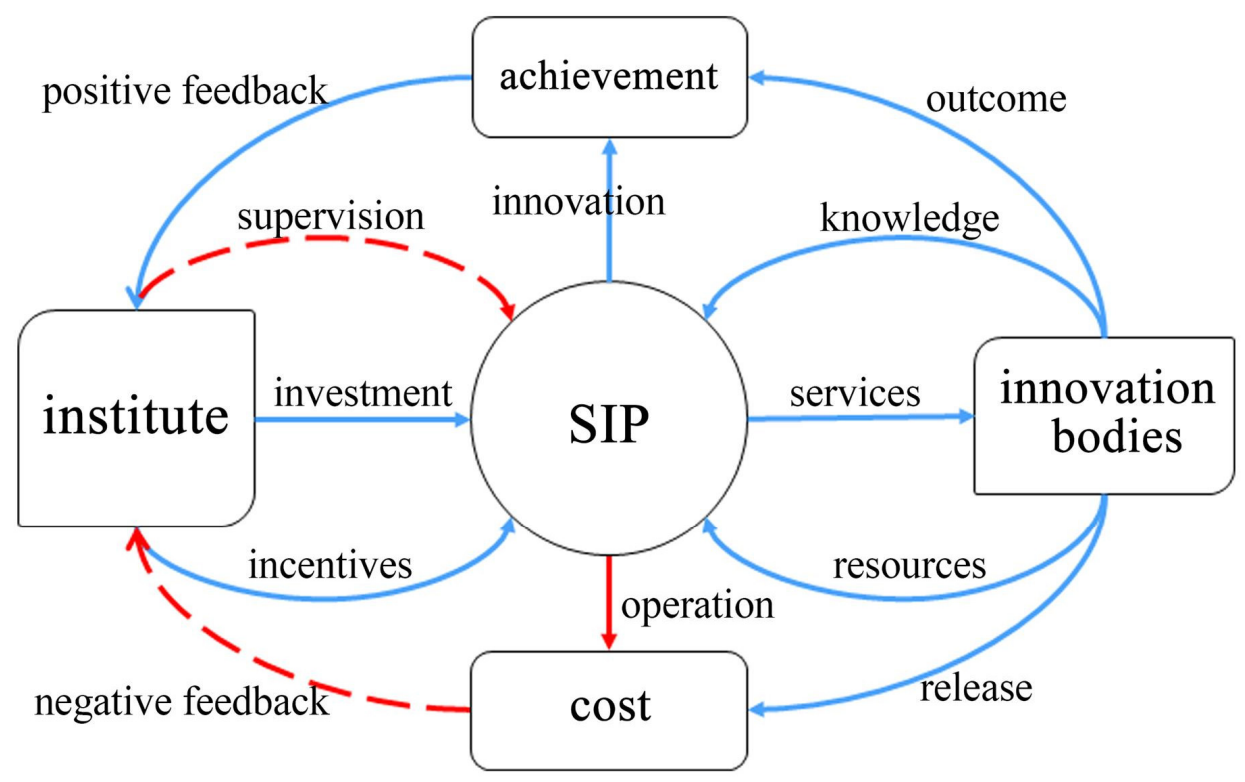

Figure 1. Functional structure network of scientific instrument platforms in CAS. The blue solid arrow means positive effect, red dotted arrow does potential negative effect, while red solid arrow contains both two effects.

Innovation in an organizational system is a complex adaptive system formulated by the interaction of social and technological factors [39]. In simple terms, a SIP in Figure 1 mode may continuously be subject to the regulation and stimulation of upper institutions such as investors and customers with multiple feedbacks, such as positive and negative chain effects and potential nonlinear effects [3]. In view of the incompleteness of the triple bottom line principle and its limitations in the operation and management process of SIPs, this study would choose the four aspects of a sustainable balanced scorecard, namely learning and growth, internal process control, customer, and finance, as the decomposition tool for the SIPs strategic objectives $[45,46]$. The effectiveness of the balanced scorecard depends on how it is interpreted and modified within a certain organization [47]. Moreover, 
the sustainability of SIPs is a multi-dimensional, multi-layered, and diversified issue, as mentioned above. With the help of group decision-making in several small seminars, this study has exhaustively enumerated the key attributes and indicators that may be involved in the operation and management of the SIPs, thus, as to fully focus on the concerns of multiple stakeholders and effectively support the definition of sustainability of the SIPs. Then, according to the importance of these indicators judged by enough stakeholders, the structural model of sustainable operation and management of SIPs would be extracted by exploratory and confirmatory factor analysis. This structural model would be a new framework for sustainability performance evaluation, in which the trade-off of ambidexterity performance was made by hundreds of SIP practitioners.

\subsection{Proposed Attributes}

Table 1 lists the attribute indicators that need to be considered during the SIPs operation and management process, referring to the classification of a balanced scorecard. The following is an elaboration.

Table 1. An enumeration of relevant indicators for scientific instruments platform.

\begin{tabular}{|c|c|c|c|}
\hline Code & Sub Goal & Indicator & Description \\
\hline $\mathrm{C} 1$ & \multirow{15}{*}{ learning and growth } & team size & $\begin{array}{l}\text { the number of people is modest, matching the scale of } \\
\text { existing instruments. }\end{array}$ \\
\hline $\mathrm{C} 2$ & & team stability & $\begin{array}{c}\text { the mobility of the team is controllable, and the } \\
\text { recruitment policy is appropriate. }\end{array}$ \\
\hline $\mathrm{C} 3$ & & team structure & $\begin{array}{l}\text { the proportion of professional tittles, education, age, } \\
\text { gender, and major is reasonable. }\end{array}$ \\
\hline $\mathrm{C} 4$ & & team incentive & $\begin{array}{l}\text { the evaluation and promotion mechanism is attractive, } \\
\text { with funds and awards of innovation. }\end{array}$ \\
\hline C5 & & staff training & $\begin{array}{c}\text { the professional training and continuing education are } \\
\text { routinely carried out. }\end{array}$ \\
\hline C6 & & staff welfare & $\begin{array}{l}\text { the salary grades and distribution mechanism are fair } \\
\text { and fascinating. }\end{array}$ \\
\hline C7 & & staff skills & $\begin{array}{l}\text { instruments operation, experimental testing, and } \\
\text { function expansion of the team are proficient. }\end{array}$ \\
\hline $\mathrm{C} 8$ & & staff innovation & $\begin{array}{l}\text { papers publication, patents authorization, and awards } \\
\text { application of the team are feasible. }\end{array}$ \\
\hline C9 & & executive candidate & $\begin{array}{c}\text { the person in charge is full-time, experienced, and } \\
\text { entrepreneurial. }\end{array}$ \\
\hline $\mathrm{C} 10$ & & leadership behavior & $\begin{array}{c}\text { the person in charge has adequately left members to } \\
\text { perform their own functions, created a developing } \\
\text { cultural way the team agrees, and maintained good } \\
\text { external relationships. }\end{array}$ \\
\hline C11 & & $\begin{array}{l}\text { independently } \\
\text { accounting }\end{array}$ & $\begin{array}{l}\text { the SIP is an autonomous department with } \\
\text { independently accounting authority and has the most } \\
\text { public scientific resources of its management unit. }\end{array}$ \\
\hline $\mathrm{C} 12$ & & strategic target & $\begin{array}{l}\text { the development direction, basic tasks, main functions, } \\
\text { and rights of the SIP are clear. }\end{array}$ \\
\hline $\mathrm{C} 13$ & & running mechanism & $\begin{array}{l}\text { the SIP is guided and guaranteed by documented } \\
\text { policies and implements self-assessments termly. } \\
\text { the senior leaders of the SIP's management unit pay }\end{array}$ \\
\hline C14 & & high-level's recognition & $\begin{array}{l}\text { attention to the SIP and actively participate in its } \\
\text { activities. }\end{array}$ \\
\hline C15 & & manager's responsibility & $\begin{array}{c}\text { the job requirements, missions, and rights of the SIP } \\
\text { executive are clear. }\end{array}$ \\
\hline $\mathrm{C} 16$ & \multirow{7}{*}{$\begin{array}{l}\text { internal process } \\
\text { control }\end{array}$} & instrument scale & $\begin{array}{l}\text { the instruments of the SIP have realized intensive and } \\
\text { scale management. }\end{array}$ \\
\hline $\mathrm{C} 17$ & & $\begin{array}{l}\text { equipment } \\
\text { progressiveness }\end{array}$ & $\begin{array}{l}\text { the existing technology and instruments are advanced, } \\
\text { updated, and influential. }\end{array}$ \\
\hline $\mathrm{C} 18$ & & quality certification & $\begin{array}{l}\text { the inspection and testing are in line with the quality } \\
\text { approval, such as ISO and CMA. }\end{array}$ \\
\hline C19 & & information construction & $\begin{array}{l}\text { the information management and multimedia have } \\
\text { been taken as basic tools, and full communication has } \\
\text { been maintained internally and externally }\end{array}$ \\
\hline $\mathrm{C} 20$ & & open sharing & $\begin{array}{l}\text { the instruments are open to the whole society and } \\
\text { have been used by several customers. }\end{array}$ \\
\hline $\mathrm{C} 21$ & & work efficiency & $\begin{array}{l}\text { the boot time of the instruments reaches the standard, } \\
\text { and the utility time is high enough. }\end{array}$ \\
\hline $\mathrm{C} 22$ & & harmoniously operating & $\begin{array}{l}\text { the team culture is positive and strong, and no } \\
\text { accidents occur all year. }\end{array}$ \\
\hline
\end{tabular}


Table 1. Cont.

\begin{tabular}{|c|c|c|c|}
\hline Code & Sub Goal & Indicator & Description \\
\hline $\mathrm{C} 23$ & & support researchers & $\begin{array}{l}\text { supporting the implementation of scientific tasks and } \\
\text { the promotion of achievements output. }\end{array}$ \\
\hline $\mathrm{C} 24$ & & technical service & $\begin{array}{l}\text { completing dissemination and training of technology, } \\
\text { communication meets, and testing analysis. }\end{array}$ \\
\hline $\mathrm{C} 25$ & & applied development & $\begin{array}{l}\text { carrying out technology research, instrument design } \\
\text { and development intended for market. }\end{array}$ \\
\hline $\mathrm{C} 26$ & customer & social responsibility & $\begin{array}{l}\text { meeting the needs of local governments and social } \\
\text { enterprises and other organizations. }\end{array}$ \\
\hline C27 & & user satisfaction & $\begin{array}{c}\text { getting customer's feedback and satisfactory } \\
\text { evaluation. }\end{array}$ \\
\hline $\mathrm{C} 28$ & & department image & $\begin{array}{l}\text { improving the image of the platform by good } \\
\text { transparency and high external recognition. }\end{array}$ \\
\hline C29 & & annual budget & $\begin{array}{l}\text { the SIP budget is adequate and fixed as a part of its } \\
\text { management unit annual budget. }\end{array}$ \\
\hline C30 & finance & stable income & $\begin{array}{l}\text { the SIP has other stable revenue sources besides the } \\
\text { fixed budget. }\end{array}$ \\
\hline C31 & & paid service & $\begin{array}{l}\text { the SIP provides services such as analysis and testing } \\
\text { with cost accounting fees. }\end{array}$ \\
\hline C32 & & financial control & $\begin{array}{l}\text { the SIP carries out effective cost control and strict } \\
\text { management of income and expenditure. }\end{array}$ \\
\hline
\end{tabular}

In terms of learning and growth, the SIP's talent team is the focal point. Team size (C1) measured by the number of regular staff is one of the basic inputs in the operation and management of SIPs [48] and an essential factor to evaluate the efficiency and benefit of sustainable development [5]. The appointment systems of engineers and technicians exists a common failing that many SIPs in China employ permanent staff with several on a contractual basis. This practice is frowned upon as being unfair in both status and welfare. Thus, talent mobility and replacement frequency are simultaneously internal and external factors that affect team stability (C2). While the distribution structure (C3) of professional titles, educational background, and age of talents, a core factor of a technical supporting team, brings the possibility of diversity and sustainable development $[17,49]$. For a technical team, the human resource system formulated for the SIP by its management unit, including incentive measures (C4), training and continuing education (C5), and salaries and welfare (C6), is the premise of optimized human resource allocation [15], and is also an important lever to adjust the process of business implementation for long-term stable development [50-52]. After a certain running-in period, the professional ability (C7) and innovative capacity (C8) shown by the technical team are the potentials of creating a first-class comprehensive research platform [53]. However, many existing studies fail to treat the executives and managers as an important and decisive part of factors that affect the performance of those organizations. Managers' attitudes, perceptions, and actions towards sustainability have a significant impact on strategic planning and the implementation of businesses related to sustainability integration [50,54]. Meanwhile, the organizational performance is often determined by its managers' tenure and their attitude towards changes [44] and can be improved by their initiative and motivation [55]. In this way, the talents factors that need to be carefully considered in the first dimension also include the candidates of SIP head (C9) and their behaviors (10) to manipulate the overall operation.

The concerns of learning and growth aspects on such factors as the training, promotion, and executive behaviors, in fact, extend to the second dimension of internal business processes. A distinction between these two aspects lies in the classification of subjective and objective factors for SIPs. The learning and growth attributes of a technical team are more active and internal than these and arise in the operation process of SIPs. Although the factors of the internal process control dimension seem to be irresistible and external, they are exactly necessary characteristics for a good management and operation state. As a serviceable and efficient organization, independent accounting (C11) is both a necessary and sufficient condition for SIPs to maintain their organizational purity nature in technical 
support [3]. Similarly, a claim of the strategic target (C12) is conductive to concentrated resource investment [56], thus that scientific and technological supporting work can be carried out more accurately and ambitiously by SIPs. Thus, SIPs can not only provide better services for different innovation bodies but also realize the benign development of their own talent team. The guarantee mechanism (C13), such as policies and measures for daily operating, should be considered as a top-level design, ensuring spontaneous problem diagnosis and reasonable adjustment measures. Here, it needs to be reexamined that the high attention of senior leaders (C14) plays an important part in the organizational operation process $[50,57]$. Leaders' high attention means enough advocating on the construction and development of SIPs with several participations in the activities and conferences of SIPs annually. The attention and recognition of high-level decision-makers, which produce and promote the sustainable development of SIPs, is an effective operational input thus that once they disappear, the effect of one vote to veto occurs [17]. Meanwhile, the authority and responsibility of the SIP head (C15), formulated by the decision-making level, determines his or her working space and constitutes the premise of sustainable leadership, which involves the contractual relationship between the managers and their organizations, the cooperation path established within stakeholders, and the values of promoting long-term sustainable development [58].

The part of factors mentioned above and relevant to top design of SIPs affects SIPs in the managing level, while another part emits its effects in the niche and operating level, which consists of instrument scale (C16), equipment progressiveness (C17), quality certification (C18), information construction (C19), open and sharing (C20), work efficiency (C21), and harmoniously operating (C22). The number of large-scale scientific instruments directly managed by SIPs reflects the extent of intensive management, with which SIPs form economies of scale to reduce operating costs and significantly increase operation efficiency [3]. On the premise of centralized management, optimized construction and instrument updating in $\mathrm{C} 17$ are a physical process to a long-term upgrading and matching of hardware and technical structures to achieve sustainable development [59]. C18 means that the contents of analytical testing are assessed by a government accredited certification body to prove that products, services, and management systems meet certain standards [60]. It makes SIPs more reliable and competitive in the market environment of internet time. These three attributes emphasize the significance of existing physical resources rather than the necessity of organizational strategy. Another four indicators related to intangible assets make SIPs available and effective. The information media in C19 is not only a tool for maintaining normal activities and complex information traffic within the organization [10], but also an important channel for disseminating real-time consultation and available resources to the external environment. C20 is a kind of organizational behavior strategy from the inside out, which meets the needs of diversified development of SIPs and concurrently confirms to the guidance of national policy and social economy stage [2]. Since the operation of instruments is the basic premise of a SIP's construction and development, the C21 becomes the basic index to measure the operating effect and reflects the presentational characteristics of scientific and technological support [17]. Last but not least, C22 means that an organization has a good team culture to effectively implement the beliefs, values, and measures of sustainable operation without any unsafe and unstable incident [57].

At the customer aspect, supporting the scientific aspect (C23) is the main interaction mode of SIP with diverse users, being the natural mission listed in the first. It is also the dominating way of collaborative innovation, which itself is one of the important innovation activities of many organizations and a key measure to maintaining long-term competitiveness [5,61]. An organization such as SIP implementing scientific support, on the other hand, usually requires the participation of long, stable, and mutual trusted customers to capture core issues, to explore research and development processes, and to solve current technical problems effectively, then to further exchange knowledge and resources with potential partners [4]. Once this situation is promoted and realized, the SIP most likely has the ability of efficient, full, and high-quality technical services (C24). 
Moreover, its regional influence might have been strengthened by the applied research and development (C25) in collaborative and autonomic work. Previous studies have identified social responsibility (C26) as a global indicator used to evaluate whether an organization has certain consequences for a particular region and human lives $[7,62]$. However, for SIPs, their social responsibility should be more a mission to evaluate their contribution to economic benefits, social development, and scientific and technological progress than regulated to complete several specific tasks. That means SIPs are essentially inseparable from the interaction with customers. Hence, user satisfaction (C27) refers to receiving customers' suggestions and opinions and inviting users to conduct satisfaction evaluations by a third party in addition to users' present feedback and ratings. If a SIP's department image $(\mathrm{C} 28)$ revealed to the outside world is transparent and communicative in the process of construction and operation, it could reduce the complexity of operation and management and promote the recognition, approval, and re-dissemination of strategic goals and organizational culture at the same time [57].

The financial attributes in the last aspect were referred to in many existing pieces of literature as the overall performance of an organization [63]. This is because financial resources help organizations deal with many operational issues [15]. However, it may be a bit different from the situation of SIPs. For a non-profit operating organization, fixed annual budget (C29) supported by its administration unit is an effective detector, which accurately mirrors the feasibility and trend of long stable operation. Meanwhile, diverse livelihood strategies help improve adaptation and resilience [64]. Abundant revenue sources (C30) financially stabilize and stimulate the efficiency on all sides of SIPs. Among various income sources, paid service (C31) priced by cost accounting is one of the important assurance conditions of SIPs and a strong proof of open sharing work [2]. It promotes and ensures the daily management and steady operation of SIPs. On the side of spending, cost control and financial process management (C32) are always integral parts of the sustainability concept, which aims to improve productivity and production efficiency [57].

\section{Data and Method}

\subsection{Case Background}

Since 2007, the competent CAS department of condition guarantee and finance has been building a 2-level scientific research supporting system, which includes several largescale instrument regional centers and dozens of institutional centers spreading all over China. By 2020, 15 large-scale instrument regional centers with more than 100 SIPs, or what the officials called institutional centers for shared technologies and facilities, were built and operating. Currently, the CAS technical support system is the largest, most standardized, and most innovative in China. In the 2018-2020 open and shared assessment of large-scale scientific instruments organized by the Ministry of Science and Technology (MOST) of China, the SIPs affiliated to the CAS have always been among the best. For example, in the first unified and normalized evaluation organized by the MOST basic condition platform center in 2018, a total of 373 management units from 21 central departments applied for and took part in the assessment on their open sharing and technical supports. Most of these management units in the evaluation were represented and spearheaded by their SIPs. There were 102 CAS SIPs participating in the national examination, accounting for $27.34 \%$ of the candidates, and 26 CAS SIPs assessed and awarded as an excellent grade, accounting for $63.41 \%$ of all the 41 outstanding. Then, the 2018 CAS excellent ratio turned out to be $25.49 \%$, far exceeding the totally excellent rate of $10.99 \%$ in China. The results showed the excellence and specificity of SIPs with the CAS construction and operation model.

The operating mode of CAS SIPs can be briefly summarized as 3 characteristics as follows. (1) Institutions first, innovative design to guarantee stability. The positioning of each comprehensive SIP was justified by administrative measures of the CAS competent department, and the operation process was actively promoted to be diversified according to different disciplines. It makes clear that rules and regulations were used to explain and implement the goal and responsibility of each SIP. (2) People-oriented, pragmatical 
cooperation to promote harmony. The CAS has taken the lead in realizing that instruments and equipment are the foundation in China, while wide technologists and even wider innovative bodies are the central part in the construction and operation of technical sharing platforms [1]. The CAS SIPs have aimed to stimulate the cooperation and mutual improvement between the technical personnel and broad scientific and technological workers to synchronously build the technical supporting system and technical talent team. (3) Virtuous circle, technological innovation to achieve sustainability. The CAS continued to facilitate its SIPs in terms of equipment updating, basic operating expenses, and post-subsidy funds. Implementing paid services for available techniques and promoting technological innovation in both new instruments' research and functions exploited not only solve the economic worries at home for the platforms themselves but also point out the development direction for their talent team, thus that the whole technical supporting system can maintain its long-term competitiveness and real influence.

\subsection{Sample and Data}

The data used in this study were collected in the form of questionnaires from September 2019 to May 2020. The preliminary design of the questionnaires was completed in May 2019. After discussion and perfection by 20 persons in charge of CAS SIPs, a questionnaire with reasonable structure, clear expression, and comprehensive content was developed and determined, whose core information is shown in Table 1. Interviewees were given a 5-point response scale ranging from 1 (very unimportant) to 5 (very important) to judge the significance of a certain indicator. The construction and operation of the CAS technical supporting system involve more than 100 units, and an accurate measurement requires that the average number of responders for each platform should be 5 to 10, including stakeholders of senior leaders, middle-level managers, and ordinary technicians [65]. The employee number of CAS technical supporting system was reported as 3195 in 2018. In order to overcome the sampling error and selection bias, the paper questionnaire and Internet media were both used to collect not less than 600 answered papers. After being put on record by the competent CAS authority, the paper questionnaires were distributed in 3 major technical symposiums held by the competent department from September to November 2019. The number of participants of each conference was about 150, mainly including leaders and principals of the competent department of the CAS technical supporting system, specially invited experts, senior leaders, platform heads, and the relevant management work and technical personnel of SIPs. In the 3 meetings, a total of 300 paper questionnaires were issued, while a total of 217 papers were collected, of which 199 were valid. Due to the low response rate and recovery, a total of 8 contacts of the large-scale instrument regional centers were one-to-one taught and entrusted to send questionnaire links to the leaders, management personnel, and at least 5 technical personnel of the member platform center within their regions. The online questionnaire was permitted to be uploaded on the condition of carefully filling in all the answers, ensuring data integrity and consistency. Simultaneously, the validity and representativeness of these data were guaranteed by the following settings, rejecting samples data from Internet protocol (IP) address outside the cities with CAS-affiliated institutes, rejecting repeated submissions with the same IP address, and rejecting answers with more than $27(90 \%)$ of the same rating in a single data. By May 2020, a total of 428 valid Internet data were collected, with another 61 pieces of information that did not meet the conditions being deleted. Finally, 627 usable survey data were returned from 25 cities. To avoid privacy issues, names, ages, and work units of responders were not required fields but optional. However, we required interviewees to give feedback on gender, educational background, position type, major, working years, and location city, as shown in Table 2. A non-parametric test was conducted for the data obtained by the paper questionnaires and online media, and there was no significant difference in the rating result of 32 attribute indicators between the 2 groups. It illustrates that the survey methods of on-paper and online have no significant influence on the sample data. 
Table 2. Demographic characteristics of sample respondents $(\mathrm{N}=627)$.

\begin{tabular}{|c|c|c|}
\hline Characteristics & Number & Percent $/ \%$ \\
\hline \multicolumn{3}{|l|}{ Gender } \\
\hline Male & 341 & 54.39 \\
\hline Female & 286 & 45.61 \\
\hline \multicolumn{3}{|l|}{ Education } \\
\hline Doctor & 218 & 34.77 \\
\hline Master & 304 & 48.49 \\
\hline Bachelor & 95 & 15.15 \\
\hline Others & 10 & 1.59 \\
\hline \multicolumn{3}{|l|}{ Position } \\
\hline Scientific & 218 & 34.77 \\
\hline Technological & 263 & 41.94 \\
\hline Managerial & 121 & 19.30 \\
\hline Assistant & 25 & 3.99 \\
\hline \multicolumn{3}{|l|}{ Major } \\
\hline Mathematics and Physics & 153 & 24.40 \\
\hline Life science (including medical science) & 157 & 25.04 \\
\hline Geoscience & 114 & 18.18 \\
\hline Material and Chemistry & 118 & 18.82 \\
\hline Advanced manufacture & 85 & 13.56 \\
\hline \multicolumn{3}{|l|}{ Years of working } \\
\hline less than 5 years & 176 & 28.07 \\
\hline 5 to 10 years & 230 & 36.68 \\
\hline 10 to 15 years & 93 & 14.83 \\
\hline more than 15 years & 128 & 20.42 \\
\hline \multicolumn{3}{|l|}{ Location city } \\
\hline Beijing & 170 & 27.12 \\
\hline Shanghai & 147 & 23.44 \\
\hline Lanzhou & 48 & 7.66 \\
\hline Guangzhou & 30 & 4.78 \\
\hline Others & 232 & 37.00 \\
\hline
\end{tabular}

In the sample data, gender factors led to significant differences $(p=0.001)$ in the rating results of responders on attribute C21. Different degrees of education take significant differences in the evaluation of $\mathrm{C} 1$ and C27, $p=0.030$ and 0.050 , respectively. Differences brought by different job positions mainly appeared in the first dimension, including C3 $(p=0.007), \mathrm{C} 5(p=0.019), \mathrm{C} 6(p=0.024), \mathrm{C} 7(p=0.045)$, and C10 $(p=0.006)$, as well as C22 ( $p=0.032)$ and C26 $(p=0.020)$. Herein, position types consisted of scientific, technological, managerial, and assistant jobs. Scientific position means the responders were mainly engaged in scientific and technology research and development within the technical supporting system, while technological positions were related to technology applications, engineering, and analysis and testing services. As shown in Table 2, the interviewees from technological positions accounted for the highest proportion, which did not conform to the overall control ratio of job types of the CAS but showed the actual position distribution in the current technical supporting system. Within the CAS system, the leading positions in managerial jobs may be full-time managers and staff in scientific or technological jobs who hold concurrent posts. Besides, managerial jobs also need administrative and routine staff whose proportion depends on the SIP positioning in their unit. Assistant positions refer to the service work of the temporary employed personnel or students, including sampling, monitoring data collection, scientific data management and processing, instrument and equipment operating, and financial business, and generally do not occupy the SIP human quota. It is obvious that any SIP is an aggregation of all 4 position types with their own business priorities leading to a different point of view on the SIP management and operation.

Although the importance of interdisciplinary communication and collaboration is always emphasized among the CAS SIPs, there were apparently essential differences 
between different professional fields. According to the management mode of the CAS SIPs, the major professional fields were divided into mathematics and physics, life science (including medical science), geoscience, material and chemistry, and advanced manufacturing of 5 types. Differences caused by professional majors were traced to C3 $(p=0.029)$, C7 $(p=0.025)$, C12 $(p=0.026)$, and C25 $(p=0.041)$. That means that some attribute indicators listed in the questionnaire may have different effects for each professional field. In addition, working years of questionnaire responders affect indicators such as C3 $(p=0.004)$, C5 $(p=0.036), \mathrm{C} 21(p=0.015), \mathrm{C} 22(p=0.015)$, and C31 $(p=0.042)$, while work locations influence C8 $(p=0.013), \mathrm{C} 10(p=0.047), \mathrm{C} 25(p=0.035)$, and C30 ( $p=0.011)$. These analyses show that there may be various factors influencing the ratings of interviewees. The more adequate the number of survey samples and the more reasonable the distribution of sample objects, the more veritable the paradigm of daily SIP operation and management. Therefore, diagnosing existing problems and identifying key factors require enough cases survey and summaries. We thought that the nearly $20 \%$ random sampling rate properly meets the requirement of the modeling analysis, thus that the result shown in this study is close enough to reality with practical significance.

\subsection{Measures}

There was a great difference in the number of indicators in the 4 dimensions constructed based on the balanced scorecard. The internal business process dimension, for instance, contains 12 attributes making the measurement process of 3 to 7 indicators controlled by a single aspect inapplicable for CFA. Moreover, there were only 4 indicators in the financial dimension, whose Cronbach's alpha coefficient calculated by sample data was only 0.409 , less than the proposed value 0.6 , indicating that the internal consistency of SIP financial indicators was not ideal. The financial dimension of SIPs should be constructed and calculated by some other attribute indicators. Given that Cronbach's alpha coefficients of the other 3 aspects were all greater than 0.6 , it demonstrates that there was still a high correlation between the proposed indicators. EFA would be used to dig the basic construction of the 32 attributes system. In this study, EFA and CFA were both achieved by Mplus, version 8 (Muthén and Muthén, 1998-2017). After that, the entropy weight method was adopted to calculate the weight value for the important information of indicators contained in the questionnaire data to analyze the priority of attribute indicators in different aspects for the next discussion $[12,66]$.

\section{Results}

\subsection{Exploratory Factor Analysis}

EFA was performed to extract 2- to 6-common factors in Mplus software, and the final extracted common factors were determined according to estimation parameters such as Chi-square value, AIC, BIC, CFI, TLI, RMSEA, and SRMR. As shown in Table 3, Chi-square values of 2- to 6-common factors models were all significant. For AIC, its values kept decreasing with the increase of the number of common factors. While BIC values decreased until the 4-common factors model and began to rise since 5-common factors model, indicating that 4- or 5-common factors may be the best extraction number with existing data. The best standard for CFI and TLI values was 0.95 , but 0.9 was generally an acceptable cutoff point. Although the CFI and TLI values showed better results under 5- and 6-common factor model, the result of 4-common factor model, was also feasible. Similarly, the recommended truncation value of RMSEA and SRMR were both 0.06 , and 4- to 6-common factor models met the requirements to become optimal solutions. Furthermore, it was found that there were marked differences between the 4- and 5-common factor models, while the differences between the 5- and 6-common factor models were not significant by the comparison results between the diverse models. It shows that the extraction results of the 5-common factor model and the 6-common factor model were similar for the proposed attributes system. It also indicates that 5-common factor model may over-subdivide the 
basic structure of the proposed attributes system. Consequently, 4-common factor model turns out to be the best result.

Table 3. Summary of model fit information.

\begin{tabular}{|c|c|c|c|c|c|c|c|}
\hline Model & Chi-Square & AIC & BIC & CFI & TLI & RMSEA & SRMR \\
\hline 2-factor & $2247.423^{* * *}$ & $43,287.207$ & $43,851.208$ & 0.611 & 0.555 & 0.082 & 0.076 \\
\hline 3-factor & $1371.332^{* * *}$ & $42,446.748$ & $43,143.976$ & 0.793 & 0.745 & 0.062 & 0.060 \\
\hline 4-factor & $647.558^{* * *}$ & $41,687.942$ & $42,513.958$ & 0.941 & 0.922 & 0.034 & 0.031 \\
\hline 5-factor & $542.625^{* * *}$ & $41,609.505$ & $42,559.867$ & 0.958 & 0.940 & 0.030 & 0.026 \\
\hline 6-factor & $530.096^{* * *}$ & $41,586.858$ & $42,657.127$ & 0.955 & 0.930 & 0.032 & 0.024 \\
\hline \multicolumn{2}{|c|}{ Models Compared } & \multicolumn{2}{|c|}{ Chi-Square } & \multicolumn{2}{|c|}{ Degrees of Freedom } & \multicolumn{2}{|c|}{$p$-Value } \\
\hline \multicolumn{2}{|c|}{2 -factor against 3-factor } & \multicolumn{2}{|c|}{1624.809} & \multicolumn{2}{|c|}{30} & \multicolumn{2}{|c|}{$* * *$} \\
\hline \multicolumn{2}{|c|}{ 3-factor against 4 -factor } & \multicolumn{2}{|c|}{738.279} & \multicolumn{2}{|c|}{29} & \multicolumn{2}{|c|}{$* * *$} \\
\hline \multicolumn{2}{|c|}{ 4-factor against 5-factor } & \multicolumn{2}{|c|}{90.323} & \multicolumn{2}{|c|}{28} & \multicolumn{2}{|c|}{$* * *$} \\
\hline \multicolumn{2}{|c|}{ 5-factor against 6 -factor } & \multicolumn{2}{|c|}{30.616} & \multicolumn{2}{|c|}{27} & \multicolumn{2}{|c|}{0.2872} \\
\hline
\end{tabular}

Note: ${ }^{* * *}$ means $p<0.001$.

To distinguish the applicability of 4- and 5-common factor model, their rotation loading matrices were provided for the comparison, as shown in Table 4. For the 5-common factor model, no attribute indicator appears a loading value greater than 0.5 in the fifth common factor. There were precisely three loadings (C10, C16, and $\mathrm{C} 17)$ more than 0.3 , but C10 shows significance within the first common factor dimension simultaneously. This result reveals a fundamental flaw for the construction of a 5-common factor hierarchical structure evaluation framework. Inversely, the 4-common factor model was chosen for its structural rationality and explanatory power. For this model, the attribute indicators with significant loadings greater than 0.5 in the first common factor included C3, C5, C6, $\mathrm{C} 7, \mathrm{C} 8$, and C10, which belong to the learning and growth dimension of the balanced scorecard approach and mainly involve the issue of talent team construction. The indicators of the second common factor consisted of C11, C12, C14, C15, and C28, which were associated with the functional positioning of SIPs. The third common factor was composed of attributes C20, C23, C24, C25, and C31, affecting the performance of the public services and interaction of demand and supply. The fourth common factor that was principally related to the internal process control of SIPs, in place of the finance aspect of the balanced scorecard, containing C19, C22, C29, and C32. To sum up, each common factor consists of not less than 3 indicators conforming to the rule of building a dimensional model, a total of 20 indicators were extracted from the proposed attributes system, and the indicator extraction rate was $62.5 \%$.

Table 4. EFA rotated loadings of 4-common factor model.

\begin{tabular}{ccccc}
\hline & F1 & F2 & F3 & F4 \\
\hline C1 & 0.016 & $0.219^{*}$ & $0.177^{*}$ & -0.006 \\
C2 & $0.171^{*}$ & $0.190^{*}$ & 0.052 & 0.044 \\
C3 & $0.863^{*}$ & -0.049 & 0.006 & 0.021 \\
C4 & $0.186^{*}$ & $0.122^{*}$ & 0.037 & 0.032 \\
C5 & $0.846^{*}$ & -0.032 & -0.050 & -0.021 \\
C6 & $0.711^{*}$ & 0.016 & -0.009 & 0.013 \\
C7 & $0.766^{*}$ & 0.054 & -0.004 & -0.064 \\
C8 & $0.672^{*}$ & 0.027 & 0.033 & 0.042 \\
C9 & $0.121^{*}$ & $0.234^{*}$ & 0.03 & $0.107 *$ \\
C10 & $0.514^{*}$ & -0.007 & -0.001 & 0.076 \\
C11 & 0.020 & $0.581^{*}$ & -0.057 & 0.004 \\
C12 & -0.004 & $0.676^{*}$ & -0.009 & 0.038 \\
C13 & 0.076 & $0.236^{*}$ & 0.035 & 0.055 \\
C14 & -0.003 & $0.588^{*}$ & 0.036 & 0.023 \\
C15 & 0.020 & $0.782^{*}$ & 0.005 & -0.038 \\
C16 & $0.178^{*}$ & 0.100 & $0.160 *$ & 0.071 \\
\hline
\end{tabular}


Table 4. Cont.

\begin{tabular}{ccccc}
\hline & F1 & F2 & F3 & F4 \\
\hline C17 & $0.136^{*}$ & $0.137^{*}$ & $0.156^{*}$ & 0.021 \\
C18 & 0.005 & 0.073 & $0.157^{*}$ & $0.101^{*}$ \\
C19 & -0.013 & $0.163^{*}$ & $-0.065^{*}$ & $0.694^{*}$ \\
C20 & $-0.105^{*}$ & 0.007 & $0.669^{*}$ & -0.011 \\
C21 & $0.173^{*}$ & 0.089 & $0.319^{*}$ & -0.017 \\
C22 & 0.038 & 0.020 & 0.060 & $0.682^{*}$ \\
C23 & -0.043 & -0.045 & $0.843^{*}$ & -0.021 \\
C24 & 0.047 & 0.017 & $0.564^{*}$ & $-0.078^{*}$ \\
C25 & $0.092^{*}$ & -0.033 & $0.531^{*}$ & $0.096^{*}$ \\
C26 & $0.116^{*}$ & -0.026 & $0.349^{*}$ & $0.118^{*}$ \\
C27 & 0.075 & 0.081 & $0.235^{*}$ & 0.022 \\
C28 & -0.065 & $0.686^{*}$ & -0.004 & -0.006 \\
C29 & -0.022 & -0.030 & 0.005 & $0.859^{*}$ \\
C30 & $0.207^{*}$ & $0.131^{*}$ & $0.117^{*}$ & -0.079 \\
C31 & -0.061 & 0.040 & $0.578^{*}$ & 0.04 \\
C32 & 0.022 & -0.017 & 0.018 & $0.787^{*}$ \\
\hline
\end{tabular}

Note: * means $p<0.05$.

\subsection{Confirmatory Factor Analysis}

According to the EFA results above, Mplus software was used for reliability and validity analysis and test in this section. The factor loading value of each indicator in all four aspects was greater than 0.5 , the significance value $(p)$ was less than 0.001 , and the coefficient of variance variation was positive, demonstrating that attribute indicators were selected effectively, as shown in Table 5. The composite reliability of each four aspects was more than the recommended 0.7 , indicating that these indicators within four new dimensions have a good consistency. The convergence validity was measured by the average variance extracted [67], whose recommended cutoff value was 0.5 but often eased to 0.36 . In Table 5, the values of F1 and F4 convergence validity conformed to the allowable values, while those of F2 and F3 were barely in accord with the acceptable one. It shows that these four aspects also have a good explanation for the 20 selected indicators. Among dimensions, the discriminant validity was measured with the square root of convergence validity as the measurement standards, which were in bold values, as shown in Table 5. Pearson correlation coefficients between dimensions showed significant positive correlation, which was less than the reference values in bold type of their own row and column, indicating that the structural model had good discriminant validity. In addition, the correlations between dimensions were all below 0.4 , which could be used to clarify the effect of collinearity among different dimensions was negligible. Thus, the structural framework extracted by EFA was proved to have a good fit by CFA.

Lastly, the Chi-square value of the 4-common factor model was tested to be 310.800 $(p<0.001)$, the degree of freedom was 164, and the ratio of the two was 1.895, falling between the propositional range of 1 to 3 . CFI and TLI values were 0.958 and 0.952 , respectively, greater than the truncation value of 0.95 . RMSEA and SRMR values were 0.038 and 0.042 , which were separately less than the suggested value of 0.06 . Therefore, the 4-common factor model can effectively extract the construction information of the proposed attribute system, which can also be used to evaluate the sustainability of SIPs.

\subsection{Weight Distribution}

The information entropy of 20 extraction attribute indicators was calculated based on the combination of entropy weight formula and the assignment frequencies of 1 to 5 for the corresponding indicators. There is a convention that when the frequency of indicators rating is 0 , the information entropy is correspondingly 0 . In this case, the information entropy weight value of these 20 indicators can be understood as the necessary degree of each attribute characteristic. According to the summation for each dimension, 
the weight value of F1 was $0.275, \mathrm{~F} 20.281, \mathrm{~F} 30.219$, and F4 0.225. In terms of necessity, F2 $>$ F1 $>$ F4 $>$ F3. Taking the average score of these indicators as the importance extent, the priority distribution diagram of these hierarchical attribute indicators can be drawn as shown in Figure 2. In the figure, the mean value of rating scores and the entropy weights were taken as the coordinate axes of the two-dimensional system, and the value space was divided into four quadrants. All selected indicators were located at the first and third quadrants, meaning that no extracted indicator was overvalued and improvable. The indicators in the first quadrant construct F2 and F4 dimensions, while the other part in the third quadrant completely forms F1 and F3 dimensions. This illustrates that in the construction and sustainable operation of CAS technological supporting system, F2 and F4 aspects have higher priority, and the attribute indicators of F1 and F3 aspects should be introduced and improved under the F2 and F4 framework.

Table 5. Reliability, convergence validity, and discriminant validity tests of the EFA result.

\begin{tabular}{|c|c|c|c|c|c|c|c|c|}
\hline \multicolumn{2}{|r|}{ Factor } & Estimate & \multirow[t]{2}{*}{$\begin{array}{l}\text { Composite } \\
\text { Reliability }\end{array}$} & \multirow[t]{2}{*}{$\begin{array}{l}\text { Average } \\
\text { Variance } \\
\text { Extracted }\end{array}$} & \multirow[t]{2}{*}{ F1 } & \multirow[t]{2}{*}{ F2 } & \multirow[t]{2}{*}{ F3 } & F4 \\
\hline \multirow{6}{*}{$\mathrm{F} 1$} & $\mathrm{C} 3$ & 0.862 & & & & & & \\
\hline & C5 & 0.830 & \multirow{5}{*}{0.875} & \multirow{5}{*}{0.545} & \multirow{5}{*}{0.738} & & & \\
\hline & C6 & 0.717 & & & & & & \\
\hline & $\mathrm{C} 7$ & 0.754 & & & & & & \\
\hline & $\mathrm{C} 8$ & 0.695 & & & & & & \\
\hline & C10 & 0.520 & & & & & & \\
\hline \multirow{5}{*}{$\mathrm{F} 2$} & C11 & 0.570 & \multirow{6}{*}{0.797} & \multirow{5}{*}{0.443} & \multirow{5}{*}{0.285} & \multirow{5}{*}{0.666} & & \\
\hline & C12 & 0.681 & & & & & & \\
\hline & C14 & 0.602 & & & & & & \\
\hline & C15 & 0.786 & & & & & & \\
\hline & C28 & 0.669 & & & & & & \\
\hline \multirow{5}{*}{ F3 } & $\mathrm{C} 20$ & 0.638 & & \multirow{5}{*}{0.414} & \multirow{5}{*}{0.129} & \multirow{5}{*}{0.190} & & \\
\hline & $\mathrm{C} 23$ & 0.879 & \multirow{4}{*}{0.772} & & & & \multirow{4}{*}{0.643} & \\
\hline & C24 & 0.546 & & & & & & \\
\hline & C25 & 0.525 & & & & & & \\
\hline & C31 & 0.564 & & & & & & \\
\hline \multirow{4}{*}{$\mathrm{F} 4$} & C19 & 0.714 & \multirow{4}{*}{0.851} & \multirow{4}{*}{0.589} & \multirow{4}{*}{0.292} & \multirow{4}{*}{0.257} & \multirow{4}{*}{0.199} & \multirow{4}{*}{0.767} \\
\hline & $\mathrm{C} 22$ & 0.709 & & & & & & \\
\hline & C29 & 0.845 & & & & & & \\
\hline & C32 & 0.794 & & & & & & \\
\hline
\end{tabular}

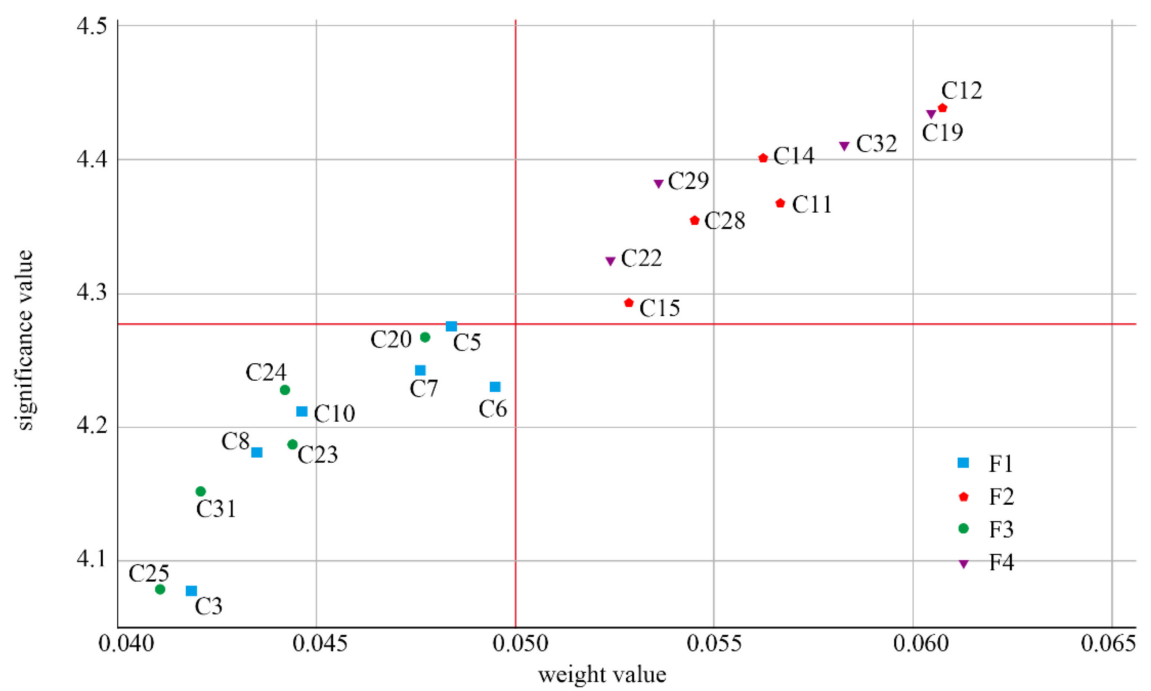

Figure 2. Importance and necessity analysis for attribute indicators of SIPs. 


\section{Discussion}

\subsection{Theoretical Implication}

This study discusses the hierarchical structure of SIPs from the perspective of organizational sustainability performance and develops an indicator framework that can be used to evaluate the sustainability of SIPs, providing a case study for the management and operation of non-profit scientific organizations. With the knowledge and experience of technological supporting systems, the evaluation system proposed by this study can not only strengthen the understanding of relevant practitioners, decision-makers, and researchers on the operation and management of SIPs, but also provide them a workable approach to pursue sustainable supporting services and development in practice. Specifically, the SIP that meets the requirements of sustainable operation and management contains four key attributes, namely platform positioning (F2), team building (F1), internal control (F4), and external service (F3). It is consistent with the connotation of SIPs analyzed by previous studies from the nominal perspective [3]. From the nominal views, the attributes of SIPs are BUFF, which is short for boundary, unity, function, and feedback four aspects. The boundary attribute corresponds to F2 aspects of the extracted indicators, which is identified to be the precondition for a sound organizational structure, job ranges, and rights and responsibilities. The unity attribute corresponds to F4, which calls for full control of the internal process in SIPs. The sound function attribute of SIPs constructed by their serviceability, professionalism, and innovativeness of the talent teams is another statement of F1. In the cooperation and interaction, there is a close correspondence between feedback attribute and F3, Both focus on the concrete actions and results of opening and sharing. Thus, the evaluation framework evolved from the balanced scorecard system totally containing the nominal attributes of SIPs, showing a serviceable and simplified function of measuring the platform sustainability performance. By extracting the basic structure of the evaluation model effectively through 627 rating data with EFA, the result finally confirms that the framework system of sustainable operation and management of SIPs includes four aspects, human resources, functional positioning, comprehensive services, and internal control.

On the other hand, this study has developed a series of attribute indicators for sustainable SIPs, which extends the exploration and regulation of the related research field. In the early years, however, the evaluation of scientific research organizations usually attached importance to the role of the three-way structure of personnel, finance, and equipment [48]. The personnel, who are broadly scientific and technological workers, has become an indispensable part of scientific activities, and the funds and scientific instruments and equipment, and thus for SIPs. Meanwhile, these three elements are essential for a normal and stable SIP. It is one-sided to only measure the current sustainable development potential from the growth and input of the three-way structure, even with integrating the output of science and technology achievement, talents, or benefits. This is because the weight of the three is unequal, and the efficiency calculated by the input and output may also need to be supplemented and improved by the requirement of personnel characteristics and the process control during operating [17]. Similarly, the management framework for large-scale scientific instruments in research enterprises and institutions has mentioned four categories of problems and challenges for effective utilization and management, namely, visibility and vision, operation and management, review and evaluation, and decision-making and investment, which are logical progressive complementary relations [68]. It is not difficult to see that visibility and vision is actually an issue about functional positioning (F2), and it is important that internal business processes and finance are under control within the operation and management aspect. It is added that both internal process control (F4) and external delegated services (F3) should be noted during perfecting and managing a SIP. Assessment and decision-making issues are beyond the responsibility and authority of an instrument management platform, though the executive of a SIP generally also has the discourse right, communicates power, and influences in the inspection work and construction seminar. Self-assessment is anyway a necessary measure to maintain healthy and steady development [3]. However, for organizations funded by central government finance, they 
may have to take external fast-updating policies and internal pending-updating positionings into account in the decision-making and investment processes due to their limited independence and irresistible regulation of the competent department. Different positions and visions bring varied preferences and concerns, thus would the evaluation results [17]. It may be a source of dilemma that most scientific research organizations have failed to deal with the choice of exploration and exploitation performance. It is also a reason that this study focuses on the mesoscopic level of the operation and management of SIPs to find out and follow the opinions of the predominant middle-level executives. Based on this, it neither excludes and mixes the internal events at the micro-level, nor introduces and magnifies the external influences at the macro level, thus, as to provide an integrated and feasible reference for the operation and management of SIPs.

\subsection{Practical Implication}

This study has also found out some implications for improving the sustainability management performance of SIPs. Although several attribute indicators were stated in previous literature on organizational sustainability performance, they have not received sufficient attention in the practices of SIP operation. This is because these pieces of work have stressed organizational sustainability, usually based on providing environmental solutions or meeting customer needs to pursue a balance between economic performance and social responsibility $[4,69]$. For the operation and management of SIPs, however, the significance of sustainability lies more in the solidity and continuity of the talent team, the advantages and professionalism of instruments and technologies, and the maintenance and interaction of customers. Corresponding to the sustainability attributes of SIPs in the four aspects of the talent team, finance, instrument and equipment, and service level, the sustainability evaluation framework extracted by EFA in this study includes top four practices, target positioning (F2), team building (F1), process control (F4), and cooperative service (F3), respectively. It suggests that stakeholders, including decision-makers and managers, should pay more attention to the substantiality of SIPs rather than only focus on substantive instruments and equipment. In other words, the instrument platform can no longer be viewed as a centralized management place but a separate entity for the construction and cultivation of a sound technological supporting system. The attributes of entities are not guaranteed by document policies (C13) or instrument scale (C16) but by actual construction with independently accounting (C11) and operable and achievable target positioning (C12). As an indispensable part and a direct support unit of basic scientific research, therefore, the goal and orientation of SIP operating management are the butting connectors, which determine whether the technological support is online. While the clients and process control are the driving parts in the functional structure network of SIPs, deciding the effectiveness and efficiency. The internal and external innovation bodies served by SIPs are regarded as customers because the interaction and cooperation between scientific researchers and technical personnel certainly belong in the category of market transactions, and their importance should be emphasized during innovation activities and need satisfaction [3]. As the rent-seeking object of SIPs, the innovation subjects are not only an important medium and mean for realizing the value of SIPs (C23, C24, and C25), but also an essential source of obtaining information, knowledge, skills, and resource feedback (C28). Since the SIP is not for profit, fixed budget support (C29) and a reasonable expenditure system (C32) are necessary for effective cooperative activities and long-term stable operation. As for supplements, information construction (C19) and harmonious operation (C22) are there to ensure the overall sustainability of the platform both physically and psychologically.

In terms of talent team, team size (C1) is considered as a basic parameter rather than a key indicator affecting the sustainability performance of a SIP. Although in the technological alliance system constructed by the CAS SIPs, it was mentioned in many formal and informal seminars that the evaluation criterion of $\mathrm{C} 1$ was not just the number of the size, but the matching extent to the number of large-scale scientific instruments within 
the platform, especially the ratio of the instrument number to the number of full-time staff. In a research institution of 500 to 1000 people where there are 50 to 100 communal and general-purpose scientific instruments, for instance, the number of public technicians can be empirically controlled at a scale of 20 to 30 . In addition, the personnel relationship of the in-service staff in SIPs is an inevitable factor for experts to review in the regular assessment and evaluation organized by the CAS competent department. The proportion of full-time and part-time jobs (C2) is not widely accepted as a kernel parameter, while what plays a decisive role in a technical team is the structure (C3), which is embodied in the distribution of professional title, education level, age, gender, and major field. Under a reasonable rank echelon of professional titles, their promotion and business succession have become orderly, and personnel incentive (C4) is no longer a limiting factor that chokes off development and operation. Involving fairness, professionalism, and stability, labor compensation (C6) was deemed as a powerful lever that would cause the team to mobilize their potentialities and needs to be carefully dealt within SIP operating. Meanwhile, communication and training (C5) are the main approaches to cultivate horizontal professional capacity (C7) and vertical innovation ability (C8), which two constitute a comprehensive service platform. Except for these eight indicators, the platform leader on the top of the hierarchy structure of the talent team in a SIP, who is a key member, was overlooked all along. This leads to the biggest missing link in the SIP operation, which contains the consequences caused by the invalidation of the leaders' social intelligence and subjective initiative $[3,65]$. This study shows that the on-job behaviors of platform executives (C10), rather than the selection of candidates (C9), were the influential factor for the sustainable operating management of SIPs. It can also be understood that what is important is not who the platform head is, but what he or she does, in which the importance of subjective awareness and practical actions of the platform leaders are stressed again. Although institutions associated with leadership are often sticky or elastic, changing existing leadership institutions to reshape the policy environment for innovation systems is clearly still a difficult and multi-authority task for the practitioners [39]. The platform leaders can also fully carry out many actions conducive to the development of SIPs within these flexibilities if they want. Therefore, the platform heads and even senior leaders should make full use of their social intelligence (empathy, coordination, organizational awareness) and relationship management skills (influence, teamwork, developing others) to create a common culture for platform operation and team growth, and to address innovation and efficiency issues [70].

The four aspects of F1 to F4 are extracted from the same attribute indicator system and seem to be a four-in-one organization pattern. However, they may exactly have a hierarchical structure. This is because there are some differences in priority between the four dimensions. As shown in Figure 1, there are sequence and spatiotemporal dynamics available among the attribute characteristics of SIP functional network. The operating process of SIPs involves two or more nested sub procedures [17]. Akin to treating the plight of exploration and exploitation in organizational management research, subdividing the organization management process has also been the predicament confronted to those ambitious managers and decision-makers. Fortunately, the equilibrium relationship between creativity and productivity performance of interaction at both macro and micro levels is finally reflected in the priorities of the four SIP dimensions ranked by the senior leaders and their executive managers. Usually, senior leaders and decision-makers are looking for benefits at the macro level, focusing on F3 and F4. However, to ensure sustainability, they need to prioritize relevant attributes in the F2 dimension. For managers and other business people, on the contrary, F1 and F3 are focuses of interest at medium, micro, and even niche levels. They may tend to evade the restrictions from F4 and ignore the regulations of F2. In this regard, there is still a lack of in-depth research on the interaction between the four dimensions and fails to observe the preferences among different perspectives of those stakeholders in this study. Alignment of values and preferences between superiors and subordinates, however, is apparently helpful to maintain and manipulate a stable and sustainable SIP. 


\section{Conclusions}

If there is no win-win situation during operating a SIP, there should be inadequacies in its operation and management, either conservative decision-making from the top level or some deviation of the middle management. According to the knowledge and evaluation of 627 scholars, decision-makers, and practitioners from CAS, this study points out and provides a hierarchical evaluation framework with four principal components of team building, target positioning, external service, and process control, which include 20 attribute indicators that help these practitioners and policymakers find and figure out the problems. The analytical results indicate that the priority of platform positioning and internal process control for a SIP is higher than that of team building and cooperative service, meaning that an agreement on platform positioning and internal control mechanism between different stakeholders is the premise for team building and external service. There are many factors involved in the operation and management of SIPs, of which this study has pointed out 20 attribute indicators by concentrating on CAS SIP operation in a recent period for the reference and discussion of decision-makers, practitioners, and scholars.

There are limitations in this study yet. Firstly, this study attempts to reflect the relevant attributes of the actual operation and management of SIPs in China, but the research objects are only confined to the CAS, which is the best performer in constructing and operating SIPs. The organizational form of CAS SIPs is obviously a special one, indicating that the universality and usability of the model may be inadequate and inadaptable for common scientific and educational organizations. Subsequent wide surveys are needed to cover as many SIPs as possible, and more attribute indicators may be proposed and put into a more comprehensive discussion. The rating of attribute indicators both online and on paper is mixed with uncontrollable subjective and arbitrary to the opinions and knowledge of interviewees. In addition, differentiation in perspective and preferences of respondents and differences in feedback from different levels or positions have failed to be identified. It leads to a confusion of information from various sources. For this, it may be necessary to further integrate the actual operation data of the SIPs and the suggestions of different stakeholders to improve the evaluation framework. The next work identifies the causal relationship between different dimensions based on the perspectives of multipartite stakeholders to implement and improve the evaluation framework and then to provide customized services for specific SIPs. In addition, by investigating and evaluating the operation and management of different SIPs and using the heterogeneity between platforms to explain the influence of some attributes, it may be more helpful to clarify the importance and influence of these attribute indicators and to give the SIPs in need a template to achieve improvement and promotion. In summary, this study is more about showing the key points and operating status of the operation and management of SIPs under the mode of CAS in the second decade of a new millennium for peer-group references around the world.

Author Contributions: Conceptualization, X.W. and X.Z.; investigation, X.W.; methodology, X.W., X.Z. and C.Z.; writing—original draft, X.W.; writing—review and editing, X.W. and C.Z. All authors have read and agreed to the published version of the manuscript.

Funding: This work was supported by the CAS Independent Intellectual Subject of Lanzhou Regional Center of Large-scale Instrument for Resource and Environment (Grant No. lz201901).

Data Availability Statement: The raw data set can be found at https://www.scidb.cn/s/v2qaIn accessed on 26 October 2021, (check pending).

Acknowledgments: Thanks for the suggestions from the management committee of Lanzhou Regional Center of Large-scale Instrument for Resource and Environment and the help from those sibling regional centers.

Conflicts of Interest: The authors declare no conflict of interest. 


\section{References}

1. Lu, Y.X. Several thoughts on the construction of technical support system of Chinese academy of sciences. Bull. Chin. Acad. Sci. 2008, 6, 481-484. (In Chinese)

2. Wang, J. Strengthen Management Mechanism, Promote Open Sharing of Scientific Research Facilities and Instrument. Anal. Test. Technol. Instrum. 2020, 26, 1-2. (In Chinese)

3. Wang, X.B. Sustainable management in the large-scale scientific instruments platform. Anal. Test. Technol. Instrum. 2020, 26, 196-203, (In Chinese with English abstract).

4. Gao, S.; Qiao, R.; Lim, M.K.; Li, C.; Qu, Y.; Xia, L. Integrating corporate website information into qualitative assessment for benchmarking green supply chain management practices for the chemical industry. J. Clean. Prod. 2021, 311, 127590. [CrossRef]

5. Lee, J.; Kim, C.; Choi, G. Exploring data envelopment analysis for measuring collaborated innovation efficiency of small and medium-sized enterprises in Korea. Eur. J. Oper. Res. 2019, 278, 533-545. [CrossRef]

6. Lozano, R. Envisioning sustainability three-dimensionally. J. Clean. Prod. 2008, 16, 1838-1846. [CrossRef]

7. Tseng, M.-L.; Lim, M.K.; Wu, K.-J. Corporate sustainability performance improvement using an interrelationship hierarchical model approach. Bus. Strat. Environ. 2018, 27, 1334-1346. [CrossRef]

8. Abbas, J. Impact of total quality management on corporate green performance through the mediating role of corporate social responsibility. J. Clean. Prod. 2019, 242, 118458. [CrossRef]

9. Raisch, S.; Birkinshaw, J. Organizational Ambidexterity: Antecedents, Outcomes, and Moderators. J. Manag. 2008, 34, 375-409. [CrossRef]

10. Wu, K.-J.; Chen, Q.; Qi, Y.; Jiang, X.; Gao, S.; Tseng, M.-L. Sustainable Development Performance for Small and Medium Enterprises Using a Fuzzy Synthetic Method-DEMATEL. Sustainability 2019, 11, 4119. [CrossRef]

11. Violeta, S.; Gheorghe, I. The green strategy mix - a new marketing approach. Knowledge management and innovation in advancing economics. Anal. Solut. 2009, 1, 1344-1347.

12. Wu, K.-J.; Gao, S.; Xia, L.; Tseng, M.-L.; Chiu, A.S.; Zhang, Z. Enhancing corporate knowledge management and sustainable development: An inter-dependent hierarchical structure under linguistic preferences. Resour. Conserv. Recycl. 2019, 146, 560-579. [CrossRef]

13. Figge, F.; Hahn, T.; Schaltegger, S.; Wagner, M. The Sustainability Balanced Scorecard—Linking sustainability management to business strategy. Bus. Strat. Environ. 2002, 11, 269-284. [CrossRef]

14. Guix, M.; Font, X. The materiality balanced scorecard: A framework for stakeholder-led integration of sustainable hospitality management and reporting. Int. J. Hosp. Manag. 2020, 91, 102634. [CrossRef]

15. Hussain, T.; Edgeman, R.; Eskildsen, J.; Shoukry, A.M.; Gani, S. Sustainable Enterprise Excellence: Attribute-Based Assessment Protocol. Sustainability 2018, 10, 4097. [CrossRef]

16. Pedersen, E.R. The many and the few: Rounding up the SMEs that manage CSR in the supply chain. Supply Chain Manag. Int. J. 2009, 14, 109-116. [CrossRef]

17. Wang, X.B.; Wang, J.; Zhao, L. Efficiency Evaluation of Scientific Instruments Platform based on Two-stage Date Envelope Analysis. Sci. Technol. Manag. Res. 2021, 41, 57-63, (In Chinese with English abstract).

18. Udo, V.E.; Jansson, P.M. Bridging the gaps for global sustainable development: A quantitative analysis. J. Environ. Manag. 2009, 90, 3700-3707. [CrossRef]

19. Elkington, J. Cannibals with Forks: The Triple Bottom Line of 21st Century Business; Capstone: Mankato, MN, USA, 1997.

20. Wu, K.-J.; Liao, C.-J.; Tseng, M.; Chiu, K.K.-S. Multi-attribute approach to sustainable supply chain management under uncertainty. Ind. Manag. Data Syst. 2016, 116, 777-800. [CrossRef]

21. Lozano, R. Towards better embedding sustainability into companies' systems: An analysis of voluntary corporate initiatives. J. Clean. Prod. 2012, 25, 14-26. [CrossRef]

22. Ahi, P.; Searcy, C. A comparative literature analysis of definitions for green and sustainable supply chain management. J. Clean. Prod. 2013, 52, 329-341. [CrossRef]

23. Wolf, J. The Relationship Between Sustainable Supply Chain Management, Stakeholder Pressure and Corporate Sustainability Performance. J. Bus. Ethic. 2013, 119, 317-328. [CrossRef]

24. Rabbani, A.; Zamani, M.; Yazdani-Chamzini, A.; Zavadskas, E.K. Proposing a new integrated model based on sustainability balanced scorecard (SBSC) and MCDM approaches by using linguistic variables for the performance evaluation of oil producing companies. Expert Syst. Appl. 2014, 41, 7316-7327. [CrossRef]

25. Lu, M.T.; Hsu, C.C.; Liou, J.J.; Lo, H.W. A hybrid MCDM and sustainability-balanced scorecard model to establish sustainable performance evaluation for international airports. J. Air Transp. Manag. 2018, 71, 9-19. [CrossRef]

26. Faber, N.; Jorna, R.; Van Engelen, J.O. The sustainability of "sustainability"-A study into the conceptual foundations of the notion of "sustainability". J. Environ. Assess. Policy Manag. 2005, 7, 1-33. [CrossRef]

27. Van Reijsen, J.; Helms, R.; Batenburg, R.; Foorthuis, R. The impact of knowledge management and social capital on dynamic capability in organizations. Knowl. Manag. Res. Pract. 2015, 13, 401-417. [CrossRef]

28. Liu, Y.; Chan, C.; Zhao, C.; Liu, C. Unpacking knowledge management practices in China: Do institution, national and organizational culture matter? J. Knowl. Manag. 2019, 23, 619-643. [CrossRef]

29. Loon, M. Knowledge management practice system: Theorising from an international meta-standard. J. Bus. Res. 2019, 94, 432-441. [CrossRef] 
30. Nisar, T.M.; Prabhakar, G.; Strakova, L. Social media information benefits, knowledge management and smart organizations. J. Bus. Res. 2019, 94, 264-272. [CrossRef]

31. March, J. Exploitation and exploitation in organizational learning. Organ. Sci. 1991, 2, 71-84. [CrossRef]

32. Mueller, J.; Renzl, B.; Will, M.G. Ambidextrous leadership: A meta-review applying static and dynamic multi-level perspectives. Rev. Manag. Sci. 2018, 14, 37-59. [CrossRef]

33. Luo, Y.; Rui, H. An ambidexterity perspective toward multinational enterprises from emerging economies. Organ. Sci. 2009, 13, 48-63. [CrossRef]

34. Martins, V.; Rampasso, I.; Anholon, R.; Quelhas, O.; Filho, W.L. Knowledge management in the context of sustainability: Literature review and opportunities for future research. J. Clean. Prod. 2019, 229, 489-500. [CrossRef]

35. Brundtland, G. Our Common Future, World Commission on Environment and Development; Oxford University Press: Oxford, UK, 1987.

36. World Bank. The Changing Wealth of Nations: Measuring Sustainable Development in the New Millennium; World Bank: Washington, DC, USA, 2011.

37. Kersten, W.; Crul, M.; Geelen, D.; Meijer, S.; Franken, V. Engaging beneficiaries of sustainable renovation-Exploration of design-led participatory approaches. J. Clean. Prod. 2015, 106, 690-699. [CrossRef]

38. Song, M.; Zhou, Y. Quantitative Analysis of Foreign Trade and Environmental Efficiency in China. Emerg. Mark. Finance Trade 2015, 52, 1647-1660. [CrossRef]

39. Anadon, L.D.; Chan, G.; Harley, A.G.; Matus, K.; Moon, S.; Murthy, S.L.; Clark, W.C. Making technological innovation work for sustainable development. Proc. Natl. Acad. Sci. USA 2016, 113, 9682-9690. [CrossRef]

40. Grin, J.; Rotmans, J.; Schot, J. The dynamics of transitions: A socio-technical perspective-a multi-level perspective on transitions. In Transitions to Sustainable Development: New Directions in the Study of Long Term Transformative Change; Grin, J., Rotamans, J., Schot, J., Eds.; Routledge: New York, NY, USA, 2010; pp. 18-28.

41. Asif, M.; Searcy, C.; Zutshi, A.; Ahmad, N. An integrated management systems approach to corporate sustainability. Eur. Bus. Rev. 2011, 23, 353-367. [CrossRef]

42. Engert, S.; Baumgartner, R.J. Corporate sustainability strategy-Bridging the gap between formulation and implementation. $J$. Clean. Prod. 2016, 113, 822-834. [CrossRef]

43. Joshi, S.; Li, Y. What Is Corporate Sustainability and How Do Firms Practice It? A Management Accounting Research Perspective. J. Manag. Account. Res. 2016, 28, 1-11. [CrossRef]

44. Damanpour, F. Organizational Innovation: A Meta-Analysis of Effects of Determinations and Moderators. Acad. Manag. J. 1991, 34, 555-590.

45. Kaplan, R.S.; Norton, D.P. The balanced scorecard-measures that drive performance. Harv. Bus. Rev. 1991, 70, 71-79.

46. Hansen, E.G.; Schaltegger, S. The Sustainability Balanced Scorecard: A Systematic Review of Architectures. J. Bus. Ethic 2014, 133, 193-221. [CrossRef]

47. Medsen, D.; Stenheim, T. Perceived problems associated with the implementation of the balanced scorecard: Evidence from Scandinavia. Probl. Perspect. Manag. 2014, 12, 121-131.

48. Guan, Z.C.; Zhang, Y. Study on evaluation models for relative efficiency for scientific research organization. Chin. J. Manag. Sci. 2003, 5, 90-95. (In Chinese)

49. Edgeman, R.L.; Fraley, L.A. A System of Profound Consciousness: Building beyond Deming. Total. Qual. Manag. Bus. Excel. 2008, 19, 683-707. [CrossRef]

50. Lozano, R. A holistic perspective on corporate sustainability drivers. Corp. Soc. Responsib. Environ. Manag. 2013, 22, 32-44. [CrossRef]

51. Yusr, M.M.; Mokhtar, S.S.M.; Othman, A.R.; Sulaiman, Y. Does interaction between TQM practices and knowledge management processes enhance the innovation performance? Int. J. Qual. Reliab. Manag. 2017, 34, 955-974. [CrossRef]

52. Kornelakis, A. Why are your reward strategies not working? The role of shareholder value, country context, and employee voice. Bus. Horizons 2018, 61, 107-113. [CrossRef]

53. Lai, K.; Chen, R.; Zhong, N. Air Pollution and Chronic Cough in China: Response. Chest 2013, 144, 363-364. [CrossRef]

54. Maon, F.; Lindgreen, A.; Swaen, V. Thinking of the organization as a system: The role of managerial perceptions in developing a corporate social responsibility strategic agenda. Syst. Res. Behav. Sci. 2008, 25, 413-426. [CrossRef]

55. Damanpour, F.; Sanchez-Henriquez, F.; Chiu, H.H. Internal and External Sources and the Adoption of Innovations in Organizations. Br. J. Manag. 2018, 29, 712-730. [CrossRef]

56. Martinsons, M.; Davison, R.; Huang, Q. Strategic knowledge management failures in small professional service firms in China. Int. J. Inf. Manag. 2017, 37, 327-338. [CrossRef]

57. Tseng, M.L.; Wu, K.J.; Ma, L.; Kuo, T.C.; Sai, F. A hierarchical framework for assessing corporate sustainability performance using a hybrid fuzzy synthetic method-DEMTATEL. Technol. Forecast. Soc. Chang. 2019, 144, 524-533. [CrossRef]

58. Lloret, A. Modeling corporate sustainability strategy. J. Bus. Res. 2016, 69, 418-425. [CrossRef]

59. Arbaa, O.; Varon, E. The role of active management and asset allocation policy on government and corporate bond fund returns. Borsa Istanb. Rev. 2018, 18, 167-175. [CrossRef]

60. Hussain, M.; Khan, M.; Al-Aomar, R. A framework for supply chain sustainability in service industry with Confirmatory Factor Analysis. Renew. Sustain. Energy Rev. 2016, 55, 1301-1312. [CrossRef] 
61. Rao, P. Greening the supply chain: A new initiative in South East Asia. Int. J. Oper. Prod. Manag. 2002, 22, 632-655. [CrossRef]

62. Chardine-Baumann, E.; Botta-Genoulaz, V. A framework for sustainable performance assessment of supply chain management practices. Comput. Ind. Eng. 2014, 76, 138-147. [CrossRef]

63. Cavaco, S.; Crifo, P. CSR and financial performance: Complementarity between environmental, social and business behaviours. Appl. Econ. 2014, 46, 3323-3338. [CrossRef]

64. Melvani, K.; Bristow, M.; Moles, J.; Crase, B.; Kaestli, M. Multiple livelihood strategies and high floristic diversity increase the adaptive capacity and resilience of Sri Lankan farming enterprises. Sci. Total. Environ. 2020, 739, 139120. [CrossRef] [PubMed]

65. Katou, A.; Budhwar, P.; Patel, C. A trilogy of organizational ambidexterity: Leader's social intelligence, employee work engagement and environmental changes. J. Bus. Res. 2021, 128, 688-700. [CrossRef]

66. Li, X.; Cundy, A.B.; Chen, W. Fuzzy synthetic evaluation of contaminated site management policy from the perspective of stakeholders: A case study from China. J. Clean. Prod. 2018, 198, 1593-1601. [CrossRef]

67. Fornell, C.; Larcker, D. Evaluating structural Equation Models with Unobservable variables and measurement error. J. Mark. Res. 1981, 18, 39-50. [CrossRef]

68. Haley, R. A framework for managing core facilities within the research enterprise. J. Biomol. Tech. 2009, 20, 226-230.

69. Fernando, Y.; Jabbour, C.; Wah, W. Pursuing green growth in technology firms through the connections between environmental innovation and sustainable business performance: Does service capability matter? Resour. Conserv. Recycl. 2019, 141, 8-20. [CrossRef]

70. Bednall, T.C.; Rafferty, E.A.; Shipton, H.; Sanders, K.; Jackson, J.C. Innovative behavior: How much transformational leadership do you need? Br. J. Manag. 2018, 29, 796-816. [CrossRef] 